\title{
EDITORAL
}

\section{UM RETRATO DOS GRUPOS DE PESQUISA DA FISIOTERAPIA E TERAPIA OCUPACIONAL NO BRASIL}

\author{
Patrícia Lordêlo*, Kátia Sá** \\ * Doutora em Medicina e Saúde Humana, Docente permanente da Pós-graduação nos programas Medicina e Saúde \\ Humana e Tecnologias em Saúde. E-mail: pvslordelo@hotmail.com \\ ** Doutorado em Medicina e Saúde Humana pela Escola Bahiana de Medicina e Saúde Pública. Atualmente é professora \\ adjunta da Escola Bahiana de Medicina e Saúde Pública. E-mail: katia.sa@bahiana.edu.br
}

O Conselho Nacional de Desenvolvimento Científico e Tecnológico (CNPq), criado em 1951, é uma agência do Ministério da Ciência, Tecnologia e Inovação (MCTI), que tem o intuito de apoiar a formação e absorção de recursos humanos e financiar projetos de pesquisa, com este objetivo desenvolveu um Diretório dos Grupos de Pesquisa no Brasil que constitui-se por uma bases de dados e que contém informações sobre os grupos de pesquisa em atividade no País. A necessidade da formação surgiu pois existia a dificuldade de identificar a quem seria destinado o apoio proposto, além de registrar as informações com o intuito de disponibilizar para a sociedade a estrutura destes grupos. (1)

Grupo de pesquisa é a denominação atribuída a uma equipe de pesquisadores, titulados ou em formação, que desenvolvem as atividades de produção do conhecimento científico. Que apresenta uma estrutura organizacional por meio da formação de uma ou mais linhas de pesquisa de uma determinada área do conhecimento, e tem como objetivo o desenvolvimento da ciência. ${ }^{(1)}$

A estrutura organizacional de um grupo de pesquisa dá-se por um pesquisador, geralmente com a titulação de doutor, que é o responsável pela liderança deste grupo, "o mentor", sendo a ele destinada a responsabilidade de gerar perguntas de investigação que serão desenvolvidas pelos outros pesquisadores. E a capacidade de desenvolvimento deste grupo não se processa pela simples presença das diversos níveis do saberes, mas sim pela interação efetiva das diversidades e pela capacidade integrativa do líder exerce sobre os seus membros e o envolvimento dos mesmo. (2)

O Diretório é hoje capaz de descrever com precisão os limites e o perfil geral da atividade científico-tecnológica no Brasil. Igualmente é capaz de fornecer aos interessados uma grande e diversificada massa de informação sobre detalhes de quem realiza as atividades, como e onde se realizam e sobre o que pesquisam cada grupo de pesquisa. (1) Utilizando este banco de dados e buscando assim descrever uma visão panorâmica sobre do grupo de pesquisa de Fisioterapia e Terapia Ocupacional no cenário brasileiro fizemos um mapeamento dos núcleos de pesquisa registrados no diretório de grupos do CNPq. (3)

Considerando o ano de formação dos grupos, constata-se um crescimento contínuo, do número de grupos de pesquisas Fisioterapia e Terapia Ocupacional no Brasil, com um maior número de registros por ano em 2010, com uma concentração na região Sul e Sudeste. A descrição referente ao ano de for- 
mação, região, número de pesquisadores, estudantes e técnicos desses grupos pode ser visualizada na Tabela 1. A progressiva ampliação do número dos grupos de pesquisa reflete a disseminação da pesquisa na área de Fisioterapia, nas diversas instituições de ensino e pesquisa brasileiras e consequentemente na produção científica. ${ }^{(4)}$

Tabela 1 - Caracterização dos Grupos de Pesquisa na área do conhecimento: Fisioterapia e Terapia Ocupacional, cadastrados no CNPq, no período de 1989 a 2012

\begin{tabular}{|c|c|c|c|c|c|}
\hline REGIÃo/PeríOdo & $\begin{array}{l}\text { NÚMERO DE } \\
\text { GRUPOS }\end{array}$ & $\begin{array}{l}\text { NÚMERO DE } \\
\text { LINHAS }\end{array}$ & $\begin{array}{c}\text { NúMERO DE } \\
\text { PESQUISADORES }\end{array}$ & $\begin{array}{l}\text { NÚMERO DE } \\
\text { ESTUDANTES }\end{array}$ & $\begin{array}{l}\text { NúMERO DE } \\
\text { TÉCNICOS }\end{array}$ \\
\hline
\end{tabular}

\section{Centro-Oeste}

$\begin{array}{llcccc}2001-2004 & 1 & 2 & 9 & 5 & 1 \\ 2005-2008 & 2 & 10 & 8 & 10 & 0 \\ 2009-2012 & 6 & 20 & 46 & 84 & 2\end{array}$

\section{NORDESTE}

$\begin{array}{llllll}1993-1996 & 1 & 15 & 22 & 23 & 0 \\ 2001-2004 & 5 & 13 & 68 & 99 & 8 \\ 2005-2008 & 8 & 20 & 56 & 117 & 2 \\ 2009-2012 & 13 & 39 & 82 & 120 & 17\end{array}$

NORTE

$\begin{array}{llcccc}2005-2008 & 1 & 5 & 8 & 8 & 2 \\ 2009-2012 & 5 & 12 & 39 & 15 & 1\end{array}$

\section{SUDESTE}

$\begin{array}{lccccc}1989-1992 & 6 & 18 & 35 & 50 & 7 \\ 1993-1996 & 3 & 5 & 23 & 11 & 6 \\ 1997-2000 & 11 & 41 & 73 & 148 & 17 \\ 2001-2004 & 28 & 80 & 172 & 196 & 16 \\ 2005-2008 & 49 & 127 & 340 & 524 & 23 \\ 2009-2012 & 38 & 111 & 184 & 224 & 11\end{array}$

SUL

$\begin{array}{lccccc}1993-1996 & 1 & 8 & 3 & 25 & 0 \\ 1997-2000 & 4 & 16 & 38 & 39 & 3 \\ 2001-2004 & 11 & 41 & 91 & 108 & 3 \\ 2005-2008 & 21 & 61 & 139 & 179 & 9 \\ 2009-2012 & 12 & 31 & 52 & 102 & 1 \\ \text { TAIS } & \mathbf{2 2 6} & \mathbf{6 8 5} & \mathbf{1 4 8 8} & \mathbf{2 0 8 7} & \mathbf{1 2 9}\end{array}$

Não foi possível analisar quando ao caráter interdisciplinar, mas pode-se inferir que este aspecto também venha crescendo baseada em informações de diferentes objetos de estudos e marcada por diversos processos de investigação. (5) Assim como a possibilidade de troca e interação desses atores 
em eventos da área e produções acadêmicas, o que serviria para expandir o número de grupos.

Espera-se com este texto ter mostrado a potencialidade que os grupos de pesquisa na área de Fisioterapia possuem, além de alertar para a necessidade de formação de grupos de pesquisa na área da Fisioterapia e Terapia Ocupacional, com uma maior distribuição quanto ao número de grupos por regiões no Brasil.

Para finalizar, recomendamos a leitura dos artigos que são apresentados nesta edição, assim como o trabalho em equipe para fortalecer um crescimento ainda maior da Fisioterapia.

Esperamos a contribuição de todos para os próximos números. Tenham uma boa leitura!

\section{REFERÊNCIAS}

1. Conselho Nacional de Pesquisa e Desenvolvimento Tecnológico. (2O12). Diretório dos grupos de pesquisa. Recuperado em 12 abril, 2015, de http://lattes.cnpq.br/web/dgp.

2. SCHRAIBER, Lilia Blima et al. Planejamento, gestão e avaliação em saúde: identificando problemas. Ciência e Saúde Coletiva, v. 4, n. 2, p. 221-242, 1999.

3. Conselho Nacional de Pesquisa e Desenvolvimento Tecnológico. (2O12). Diretório dos grupos de pesquisa. Recuperado em 12 abril, 2O15, de http://dgp.cnpq.br/planotabular/ index.jsp http://dgp.cnpq.br/buscagrupo/

4. Sá, K.N. ; Lordêlo, P. The contribution of scientific journals for the development of physiotherapy. Revista Pesquisa em Fisioterapia, v. 4, p. 96-98, 2014

5. Conselho Nacional de Pesquisa e Desenvolvimento Tecnológico. (2O12). Diretório dos grupos de pesquisa. Recuperado em 12 abril, 2015, de http://dgp.cnpq.br/buscagrupo/ 